\title{
Christian Kreuder-Sonnen. 2019. Emergency Powers of International Organizations: Between Normalization and Containment. (Oxford: Oxford University Press)
}

\author{
Felicity Vabulas ${ }^{1}$ (D)
}

Published online: 29 June 2020

(C) Springer Science+Business Media, LLC, part of Springer Nature 2020

Alongside the promise of international cooperation lies a growing concern regarding the potential overreach of international organizations (IO). Scholars and policy-makers alike wonder how transnational actors can constrain IOs and ensure they are legitimate and accountable in our system of global governance. At the heart of this dilemma is the potential abuse or misuse of institutional power; yet these crucial concerns become even more pronounced during and after emergency rule. In Emergency Powers of International Organizations: Between Normalization and Containment, Christian Kreuder-Sonnen asks how and why some IOs extend emergency powers to become quotidian rule while other IOs draw down and regulate these emergency powers. Much of what we know about IOs centers on the procedures and norms that define routine collective policy. Yet this book makes a persuasive argument that the crisis politics of IOs can delineate the conditions under which IOs expand their mandates or maintain the status quo. Kreuder-Sonnen posits that rhetorical arguments about the legitimacy of the IO's authority are at the heart of understanding when IO emergency powers will become normalized or subject to constitution-like checks. A convincing set of six cases of emergency rule at the United Nations, European Union, and World Health Organization provide the empirical testing ground for the convincing "authority leap" argument regarding when we will see ratcheting up or rollbacks of emergency powers in IOs.

It is worth underscoring that this is not a general book about how IOs operate during emergencies. Instead, it is laser focused on understanding how and when IOs expand beyond their constitutional mandate to extend emergency powers into part of the IO's commonplace processes. Kreuder-Sonnen calls IO emergency measures that have become normalized over time "ratchet effects." For example, immediately following 9/11, the UN Security Council passed Resolution 1373 (2001), outlining that

Felicity Vabulas

Felicity.Vabulas@pepperdine.edu

1 Pepperdine University, 24255 Pacific Coast Hwy, Malibu, CA 90263, USA 
international terrorism was a threat to international peace and security and criminalizing terrorism-supporting activities. In doing so, the Security Council essentially ruled by decree rather than leaning on a consent-based tradition that respects the sovereign equality of each state. By setting new rules, the Security Council assumed the role of global legislator, which changed the constitutional authority structure laid out in the UN Charter.

But Kreuder-Sonnen is equally interested in understanding the conditions under which IOs rollback these emergency powers: when do IOs reverse the powers they assumed during emergencies and constrain them through new legal constraints? For example, the H1N1 "swine flu" in 2009 prompted the World Health Organization to declare a global pandemic, triggering advance purchase agreements of drugs from pharmaceutical companies. When the swine flu turned out to be relatively mild, critics lambasted the WHO's lack of transparency and corporate overreach. These accusations prompted the WHO to accept procedural containments of its emergency powers and new rules regarding conflicts of interest. With the WHO now at the heart of the 2020 Covid-19 crisis, understanding how it extends or curtails emergency powers is no doubt critical. Kreuder-Sonnen underscores that past analyses of IO emergency powers have focused on individual cases as "singular scandals," but this book is influential because it creates a common framework for understanding IO exceptionalism as a class of events that are comparable across institutional settings. With much IO literature demarcated along issue area lines, he makes a convincing case that the expansion or retraction of emergency powers is a common concern across IOs.

Kreuder-Sonnen's argument centers on sociological institutionalism. While he acknowledges that power (realism) and IO design (institutionalism) are important in understanding the normalization (or not) of an IO's emergency powers, he argues that one cannot understand ratchet and rollback effects without considering legitimacy. When coalitions can use rhetorical leverage to argue the IO's emergency authority is commensurate with the challenge, they can legitimize the normalization of emergency rule. On the other hand, if contentious actors use convincing arguments to delegitimize emergency powers, then IOs will be forced to contain exceptional practices that intrude on states' and citizens' rights.

In explaining how variance in the distribution of rhetorical power leads to ratchets and rollbacks, Kreuder-Sonnen first leans on theories of domestic politics and emergency rule. Since almost all states have faced extraordinary circumstances that lead the executive branch to invoke discretionary rather than ordinary rule of law, he takes domestic theories to the international setting. In doing so, the book is framed to focus on how IOs handle (and learn from) standout historical moments to define their successes and failures. These domestic parallels are a welcome addition to the international organization literature. Nonetheless, he recognizes where the domestic analogy falls short-states can back emergency rule with the use of force while IOs lack similar enforcement capabilities-but this is counterintuitively what makes Kreuder-Sonnen's study so important. Even lacking the use of force, some IOs still expand their powers during exceptional times. They normalize emergency powers, he argues, by building on their authority to get states to defer to their rules. This highlights the Janus-faced nature of IO authority: while it helps IOs successfully govern, it can also result in overreach. 
Kreuder-Sonnen also leans on the concept of proportionality from just war theory to understand the threshold between legitimation (a ratchet) and delegitimation (a rollback). The more that key coalitions argue that IO emergency powers are justified as proportionate - adhering to standards of necessity, functionality, and costs - the likelier they will become entrenched. On the other hand, the more that key critics contest IO emergency powers as disproportionate, the likelier these exceptional processes will be confined. Wars are perhaps the supreme emergency in international relations, so using just war theory to understand emergency rule in IOs is both logical and effective. Kreuder-Sonnen's use of the contentious politics literature (Tilly and Tarrow 2006) because IO exceptionalism can trigger conflict from distributional effects-rounds out a cross-disciplinary approach to the research. This makes the book essential reading for broad audiences that care about how institutions form checks and balances before and after exceptional times.

The richness of Emergency Powers is bound to raise important questions. One of the biggest challenges in problematizing ratchet effects is that, from another lens, they may just be considered reforms. If augmentation of power sticks after emergency rule, is this just because normal procedures to handle emergencies were not satisfactory? This is a very different view than thinking IOs overextend undelegated powers and subsequently curtail states' sovereignty. Another challenge is that one could argue that the theory simply says that incremental changes will stick but massive changes will not. In some respects, this seems obvious. But looked at differently, these conclusions raise the concern that over time, we may see largescale emergency powers become entrenched in IOs not through one fell swoop but instead from a series of back-to-back incremental moves. This critique may then heighten the importance of the book: if we worry about abuses from emergency rule, then we should be particularly concerned that piecemeal changes might escape scrutiny but lead to systemic overhauls.

At its core, Emergency Powers argues that rhetorical power is necessary for either the pro-ratchet or pro-rollback coalition to assert its preferred outcome. Readers may therefore wonder when actors will have rhetorical power but not institutional power because the consent or acquiescence of the most powerful states is likely key. Is the ability to extend emergency powers, then, just another example of powerful states tightly controlling IOs? In some respects, this is disheartening because it shows that the weak are at the mercy of the powerful perhaps when they are most vulnerable. Yet from another angle, the mediating force of state power mitigates the concern that IOs can easily become runaway bureaucracies.

While one of the strongest aspects of the book is its domestic analogy, readers may want to push more on this foundation. It creates, for example, a strong normative angle because in the domestic context, emergency powers are constitutionally deviant. This means that Kreuder-Sonnen is also concerned with overreach because domestic emergency rule can result in the government constraining the rights of citizens. However, if an IO has "earned" more authority, it is worth considering whether it is problematic for the IO to use its authority to do more. Many IOs are set up to provide citizens' rights through safety nets during times of emergency. For example, the IMF's 'lender of last resort" status acknowledges that its role is to be powerful in the case of emergencies. Moreover, in the 2008 financial crisis, Mario Draghi affirmed that the European Central Bank (ECB) could do "whatever it takes" to restore financial stability in European 
member states ${ }^{1}$ and many observers regarded its far-reaching powers to act in extraordinary times as beneficial (and essential) to global macroeconomic stability. Follow on work should consider how we know when an IO's exceptional powers are being used "for the good" versus when they are power grabs with a dissatisfying, undemocratic underbelly. IO exceptionalism may not always produce net losers.

Another important question is the "dogs that don't bark." While Kreuder-Sonnen is right to worry about IOs overstepping their mandates, the public just as often cries out for IOs to do more to step up during emergencies. Indeed, in the concluding remarks, the author acknowledges that "the problem is not the excess but a growing lack of IO authority" (p. 207). So when do IOs not ratchet up in the first place but instead block cooperative solutions during times of crisis? When do IOs fail to invoke emergency powers that might be necessary to govern the global commons? A promising extension of the book could systematically investigate the precise conditions under which IO exceptionalism does not materialize. Relatedly, future research could derive a comprehensive bank of cases when IOs face the possibility of using emergency powers, when they use them, and when they end up falling short. This sort of comprehensive data would help readers grapple with generalizability as well as time-variant patterns (whether the use of IO emergency powers is increasing, and if so, why). Moreover, this would help link to the conditions under which IOs develop mechanisms to check their unwanted side-effects, which Heupel et al. (2018) call an "authority-legitimation mechanism."

Last, scholars of IO crisis-handling might look at emergency powers in the context of rising informality in global governance rather than just in formal IOs such as the UN, $\mathrm{EU}$, and WHO. If there really are few times when states normalize emergency powers in IOs, then perhaps we need to better understand how states use alternate forums such as informal IOs to expand power in times of crisis (Vabulas and Snidal 2020). If we worry about the accountability and transparency challenges of emergency powers in formal IOs, we might be especially concerned with how informal IOs with fewer regulations handle these crucial concerns.

In sum, Emergency Powers of International Organizations makes an important contribution to understanding how and when IOs expand and retract the exceptional power they create in times of crisis. But Kreuder-Sonnen's most important contribution is to bring theoretical and empirical heft to the explanatory power of political rhetoric (Goddard and Krebs 2015) in international relations as well as the independent effect of IO legitimacy in global governance (Tallberg and Zürn 2019).

\section{References}

Goddard, S. E., \& Krebs, R. R. (2015). Rhetoric, legitimation, and grand strategy. Security Studies, 24(1), 536.

Heupel, M., Hirschmann, G., \& Zürn, M. (2018). International organisations and human rights: What direct authority needs for its legitimation. Review of International Studies, 44(2), 343-366.

Tallberg, J., \& Zürn, M. (2019). The legitimacy and legitimation of international organizations: Introduction and framework. Review of International Organizations., 14, 581-606.

1 https://warwick.ac.uk/fac/soc/pais/research/researchcentres/ipe/publications/misp_v42_i1_journal_rev2_2. pdf\#page $=270$ 
Tilly, C., \& Tarrow, S. (2006). Contentious politics. Oxford: Oxford University Press.

Vabulas, F., \& Snidal, D. (2020). Cooperation under autonomy: Building and analyzing the informal intergovernmental organizations 2.0 data set. Journal of Peace Research. Forthcoming.

Publisher's note Springer Nature remains neutral with regard to jurisdictional claims in published maps and institutional affiliations. 